\title{
Plasma cyclic nucleotide levels in exercise-induced asthma
}

\author{
JPR HARTLEY, CJ DAVIES, TJ CHARLES, RDH MONIE, SG NOGRADY, \\ MD WINSON
}

From the Asthma Research Unit, Sully Hospital, Penarth, Department of Tuberculosis and Chest Diseases, Welsh National School of Medicine, Llandough Hospital, Penarth, and the Department of Medical Biochemistry, University Hospital of Wales, Cardiff, South Glamorgan

ABSTRACT It is known that sympatho-adrenal control of airways is increased in asthma since $\beta$ blockade can cause severe bronchoconstriction in asthmatic individuals. It has not been established whether an altered catecholamine response to exercise plays any part in the production of the common symptom of exercise-induced asthma (EIA). We have investigated this indirectly by measuring arterial plasma cyclic nucleotide levels in 10 subjects with EIA and five normal subjects. Cyclic AMP, which in this context reflects $\beta$ stimulation, rose significantly by $25.4 \%$ in the normal subjects during exercise, while there was no significant change during or after exercise $(<5 \%)$ in the asthmatic subjects. Cyclic GMP rose significantly after exercise in the asthmatic subjects. Six normal subjects repeated the protocol before and after inhalation of salbutamol aerosol, $1600 \mu \mathrm{g}$ daily for 18 days. This did not reduce the cAMP response to exercise, and we conclude that the diminished cAMP response of the asthmatic subjects was not caused by their medication. The results may indicate either impaired catecholamine production or endogenous $\beta$ receptor hyporesponsiveness in some asthmatic subjects and this may contribute to the development of EIA.

It is well known that adrenergic control of airway tone is more important in asthmatic than normal individuals. This is reflected in the common clinical observation that non-selective $\beta$ adrenergic blocking drugs may cause bronchoconstriction in asthmatics, but have little or no effect in normal people. ${ }^{1}$

Several studies have suggested that these differences may partially explain the phenomenon of exercise-induced asthma (EIA), since exercise is normally associated with increased sympathoadrenal activity, and an abnormal response in asthmatics might cause bronchial smooth muscle contraction. $^{23}$ The catecholamines adrenaline, derived from the adrenal medulla, and noradrenaline, derived largely from sympathetic nerve endings, ${ }^{4}$ can be measured in plasma, but although several studies have been performed, ${ }^{35} 6$ there is no general agreement as to whether subjects who have EIA behave differently from those who do not. Some part of this uncertainty may have arisen because of technical difficulties in assaying plasma catecholamines, and we have therefore examined changes in cyclic nucleotide levels in plasma in a group of patients with EIA and a group of normal subjects. It

Address for reprint requests: Dr JPR Hartley, Asthma Research Unit, Sully Hospital, Penarth, South Glamorgan. is known that plasma levels of cyclic adenosine $3^{\prime}: 5^{\prime}$-monophosphate (cAMP), while reflecting the actions of several hormones, are increased by catecholamines, ${ }^{7}$ while plasma cyclic guanosine $3^{\prime}: 5^{\prime}$-monophosphate (cGMP) levels can be increased by noradrenaline, ${ }^{7}$ and tissue cGMP levels are elevated by the effects of chemical mediators generated in lung tissue. ${ }^{8}$

\section{Methods}

Ten male patients with known EIA ( $>15 \%$ fall in peak expiratory flow rate, PEFR, or forced expiratory volume in one second, $\mathrm{FEV}_{1}$ after exercise) gave their informed consent to the study, which was given approval by the local ethical committee. Their ages ranged from 19-49 years (mean 32.8). Their mean weight was $68 \cdot 2 \mathrm{~kg}$. Seven were atopic on the basis of skin prick tests. All the subjects were using inhalers containing $\beta$ adrenergic bronchodilators, but three subjects had used them less than once each day for several months. The other subjects took between 200 and $800 \mu \mathrm{g}$ of salbutamol daily. In addition, four subjects used inhaled corticosteroids, one took oral prednisone, and one sodium cromoglycate. The subjects attended the laboratory for 
exercise testing on one afternoon, at least two hours after their last meal. They had not taken bronchodilator drugs or sodium cromoglycate for at least 16 hours. A Venflon cannula $(1.2 \mathrm{~mm}: 18 \mathrm{~g})$ was inserted into the radial or brachial artery under local anaesthesia, and the subjects rested for 15 minutes before the first basal blood samples were taken. Further samples were taken 15 minutes later and exercise was then performed.

Exercise was carried out on an electromagnetically braked cycle ergometer (Lode) and consisted of eight minutes of steady state sub-maximal exercise. sufficient to raise the heart rate to about $150 \mathrm{bpm}$ during the last four minutes of the test. Oxygen uptake was calculated at half-minute intervals by entering the results of inspired ventilation volume and expired gas analysis into a programmed calculator, as previously described. ${ }^{9} 10$

The response to exercise was assessed using the best of three readings of PEFR (Wright peak flow meter) and $\mathrm{FEV}_{1}$ (Vitalograph) recorded on each occasion. Measurements were made five minutes and immediately before exercise, and the average of the best values used as the baseline unless they differed by more than $10 \%$, in which case further readings were taken until a stable level was reached. Readings of PEFR and FEV 1 were made immediately after exercise and then every five minutes for 30 minutes. The results have been expressed as the maximum percentage fall in each index from the initial values.

Arterial blood samples were taken before exercise as previously described. Further samples were taken during the last minute of exercise, and then 5,15 , and 30 minutes after completion of the exercise. Volumes of $10 \mathrm{ml}$ blood were withdrawn each time, separated immediately, and the plasma deproteinised with an equal volume of trichloracetic acid (100 g/l). The supernatant was frozen and stored at $-20^{\circ} \mathrm{C}$ until assay. Cyclic AMP was measured directly by specific radioimmunoassay after addition of $\mathrm{CaCl}_{2}$ in excess of sequestrene present. ${ }^{11}$ Samples for cGMP were also measured by radioimmunoassay. ${ }^{12}$ Antisera to cyclic nucleotides were produced in rabbits after multiple intradermal injections of 2' - 0 - succinyl AMP or GMP coupled to human albumin, and were selected for use on the basis of their titre and specificity.

Five healthy non-atopic males, aged 28-39 years (mean 31.6), were also studied. Their mean weight was $76.6 \mathrm{~kg}$. Arterial sampling, exercise tests, and lung function measurements were carried out as described above.

In order to see whether the regular inhalation of a $\beta$ adrenergic agonist would alter the cAMP response, six healthy non-atopic male volunteers, aged 24-31 years (mean 29.5) were studied using the same protocol, except that venous rather than arterial samples were taken. After an initial test, all subjects inhaled salbutamol aerosol, $1600 \mu \mathrm{g}$ daily (16 puffs) for 18 days. They then performed a second exercise test having not used the inhaler for 16 hours, and the cAMP responses were compared with the first test.

Comparisons have been made using Student's $t$ test or paired $t$ tests, as appropriate, to detect significant differences.

\section{Results}

The normal and asthmatic subjects performed similar amounts of exercise, as is shown by their mean exercise responses (table 1). The response to exercise in terms of lung function differed between the groups. After exercise there was an insignficant small mean rise in both PEFR and FEV 1 , in the normal subjects of 0.36 and $0.06 \%$ respectively. In the asthmatic subjects, there was a mean maximum fall in PEFR of $19.5 \%$ and in FEV 1 of $24.2 \%$. All the asthmatics experienced a fall of at least $15 \%$ in at least one measurement after exercise.

The cyclic nucleotide responses are shown in figs 1 and 2 and table 2. Cyclic AMP rose in the normal subjects from a mean level before exercise of $19.89 \pm 0.85 \mathrm{nmol} / \mathrm{l}$ (using mean $\pm \mathrm{SEM}$ of two baseline values for each subject) to $24.94 \pm 1.0$ $\mathrm{nmol} / \mathrm{l}$ in the last minute of exercise $(+25.4 \%)$. This increase was significant $(p<0.05)$. The initial level of cAMP in the asthmatic subjects was $20.91 \pm$ $0.45 \mathrm{nmol} / 1$, which was not significantly different from the normal subjects, but there was no significant rise during or after exercise $(<1 \mathrm{nmol} / \mathrm{l},+4.4 \%)$. The difference between the cAMP levels in each group was significant at the end of exercise $(p<0.05$ and five minutes later $(\mathrm{p}<\mathbf{0 . 0 1})$. Plasma cGMP levels rose by $29 \%$ in the normal subjects during exercise, although this rise was not quite significant $(0.1>p>0.05)$. There was a rise of $17 \%$ in the asthmatic subjects, but the maximum increase was not seen until five minutes after exercise had finished. The levels five minutes and 15 minutes after exercise were both significantly higher than the initial values ( $\mathrm{p}<0.01$ and $<0.05$ respectively). At no time were

Table 1 Exercise performance during eight minutes cycling (mean values $\pm S E M$ )

\begin{tabular}{lll}
\hline Index & $\begin{array}{l}\text { Asthmatic } \\
(n=10)\end{array}$ & $\begin{array}{l}\text { Normal } \\
(n=5)\end{array}$ \\
\hline Mean maximum heart rate & $147 \pm 2$ & $146 \pm 5$ \\
Total ventilation (litres BTPS) & $335 \pm 9$ & $354 \pm 39$ \\
Total oxygen uptake (mmol)* & $586 \cdot 1 \pm 14.5$ & $627 \cdot 1 \pm 54 \cdot 8$ \\
Oxygen uptake/kg (mmol/min/kg) & $1 \cdot 10 \pm 0.05$ & $1.02 \pm 0.06$ \\
\hline
\end{tabular}

*Multiply"by $22 \cdot 4$ to convert to $\mathrm{ml}$. 


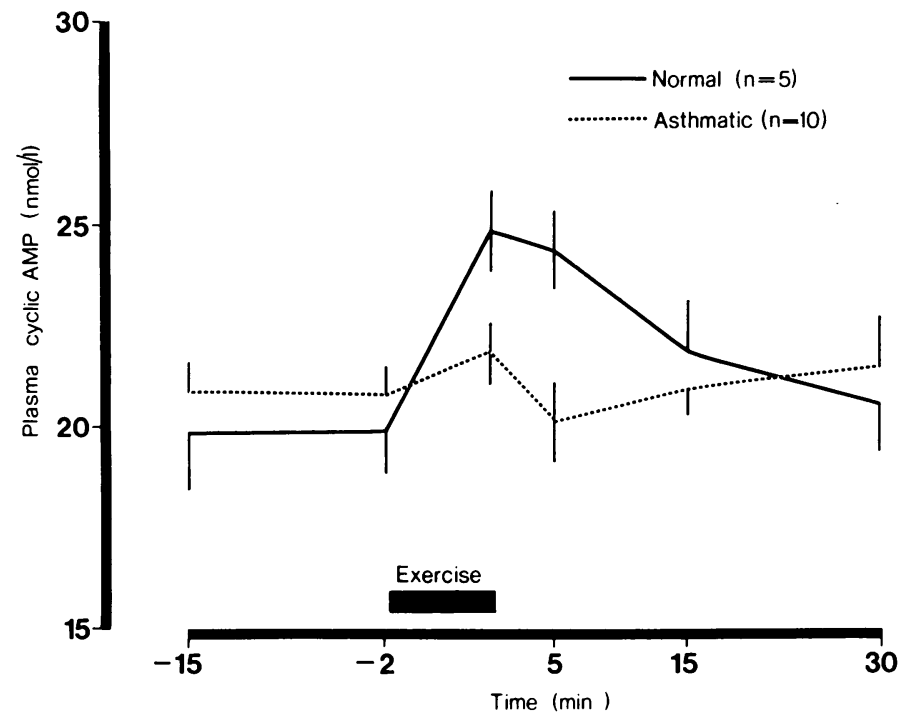

Fig 1 Arterial plasma cyclic AMP levels (mean $\pm S E M)$ before, during, and after exercise in normal and asthmatic subjects.
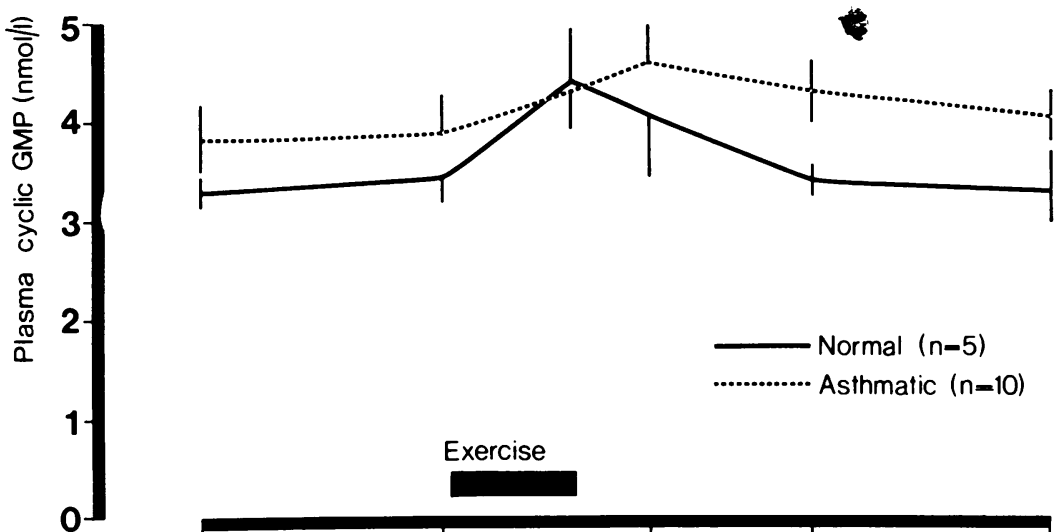

Fig 2 Arterial plasma cyclic GMP levels (mean $\pm S E M$ ) before, during, and after exercise in normal and asthmatic subjects.

Asthmatic $(n=10)$

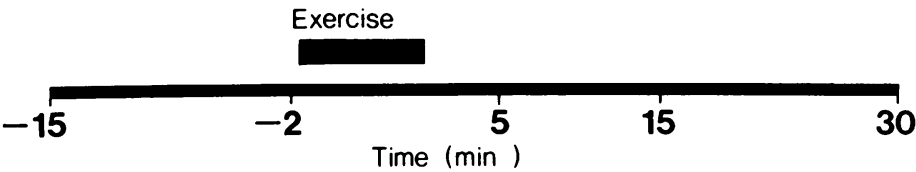

Table 2 Plasma cyclic nucleotide levels (mean $\pm S E M)$, before, during, and after exercise in normal and asthmatic subjects

\begin{tabular}{|c|c|c|c|c|c|c|}
\hline & \multicolumn{2}{|c|}{ Time before exercise (min) } & \multirow{2}{*}{$\begin{array}{c}\text { During } \\
\text { exercise }\end{array}$} & \multicolumn{3}{|c|}{ Time after exercise (min) } \\
\hline & -15 & -2 & & 5 & 1 & 30 \\
\hline \multicolumn{7}{|l|}{$\begin{array}{l}\text { Cyclic AMP } \\
(\mathrm{nmol} / \mathrm{l})\end{array}$} \\
\hline Normal & $19 \cdot 8 \pm 1 \cdot 4$ & $20 \cdot 0 \pm 1 \cdot 1$ & $24.9 \pm 1 \cdot 0$ & $24 \cdot 5 \pm 1 \cdot 0$ & $21.9 \pm 1 \cdot 3$ & $20.6 \pm 1.3$ \\
\hline Asthmatic & $21.0 \pm 0.7$ & $20.8 \pm 0.6$ & $21 \cdot 8 \pm 0.8$ & $20 \cdot 2 \pm 1 \cdot 1$ & $21 \cdot 1 \pm 0 \cdot 6$ & $21 \cdot 6 \pm 1 \cdot 3$ \\
\hline \multicolumn{7}{|l|}{$\begin{array}{l}\text { Cyclic GMP } \\
(\mathrm{nmol} / \mathrm{l})\end{array}$} \\
\hline Normal & $3.3 \pm 0.1$ & $3.4 \pm 0.2$ & $4.4 \pm 0.5$ & $4 \cdot 1 \pm 0 \cdot 7$ & $3.4 \pm 0.2$ & $3 \cdot 3 \pm 0.4$ \\
\hline Asthmatic & $3 \cdot 8 \pm 0.3$ & $3.9 \pm 0.4$ & $4.4 \pm 0.5$ & $4.6 \pm 0.4$ & $4.3 \pm 0.3$ & $4 \cdot 1 \pm 0.3$ \\
\hline
\end{tabular}

the cGMP levels between the groups significantly different.

Six normal subjects inhaled salbutamol aerosol in order to see whether regular administration of a $\beta$ adrenergic agonist would depress the cAMP response to exercise. It did not. There was no significant difference in the venous cAMP response before and after $1600 \mu \mathrm{g}$ of salbutamol daily for 
18 days. The mean cAMP level before exercise after salbutamol was $21.59 \pm 0.36 \mathrm{nmol} / \mathrm{l}$, rising to $24.25 \pm 1.0$ during the last minute of exercise $(\mathrm{p}<0.02)$.

Conversely, the three asthmatic subjects with least salbutamol inhaler usage ( < once each day for three months) reflected the general pattern of the asthmatic group. Their mean initial cAMP level was 21.0 $\pm 0.93 \mathrm{nmol} / \mathrm{l}$, and their mean level during exercise was $20.3 \pm 1.5 \mathrm{nmol} / \mathrm{l}$.

\section{Discussion}

The effects of adrenaline on its target tissues are mediated through control of the intracellular concentrations of cAMP. ${ }^{13}$ Not all cAMP remains within cells; some diffuses into tissue fluids and thence into the circulation. Plasma levels of cAMP have been used to investigate hormonal responses in vivo, ${ }^{714}$ and provide an index of tissue levels of nucleotide. ${ }^{14}$ In man the exact sources of basal plasma levels are unknown. In the dog, the lungs are an important source, but many tissues probably contribute small net amounts. The lungs are also net producers of cGMP, which is present in plasma in about one-fifth the concentration of cAMP.

In man, exogenous catecholamines have been shown to increase cyclic nucleotide levels in plasma. Adrenaline causes a rise in cAMP, but no rise in cGMP, while noradrenaline in combination with a $\beta$ blocking drug causes a rise in cGMP.? Beta stimulation therefore produces cAMP, while $\alpha$ stimulation produces cGMP. Exercise in healthy subjects is associated with increases in both adrenaline and noradrenaline plasma levels, ${ }^{16}$ and concomitant increases in plasma cAMP have been reported, ${ }^{17}$ which have been presumed to reflect catecholamine production.

We have found a significantly impaired cAMP response to exercise in asthmatic subjects, which in turn implies an altered catecholamine response. This could theoretically be diminished catecholamine production or reduced tissue response caused by a state of $\beta$ receptor hyporesponsiveness. The first possibility is at present difficult to evaluate because studies which have measured catecholamines directly have given conflicting results, possibly partly because of differences in assay methods. Some reports have found no difference between normal subjects and asthmatics, ${ }^{56}$ while some have shown a greater rise in catecholamines in asthmatics. ${ }^{3}$ Barboriak and co-workers reported a diminished rise in free fatty acids after exercise in asthmatic subjects, ${ }^{18}$ and Barnes and his colleagues, using a sensitive radioenzymatic assay have recently reported a reduced rise in catecholamines in subjects with
EIA. ${ }^{19}$

Hyporesponsiveness of $\beta$ receptors on bronchial smooth muscle has been proposed as an important part of the asthmatic diathesis. ${ }^{20}$ Many studies have confirmed the reduced in vitro responses of asthmatic tissues, particularly lymphocytes, to exogenous $\beta$ adrenergic agonists, but have attributed this to previous regular administration of bronchodilator drugs. ${ }^{21}$ In this study, administration of salbutamol for 18 days, in a dose which was twice that used for bronchodilatation and which has been reported to produce tolerance to airway responses, ${ }^{22}$ did not reduce the cAMP response to the asthmatic level. Asthmatic subjects who had used little salbutamol for many months still failed to produce cAMP on exercise. Thus, if any partial $\beta$ blockade were present, it would appear to be endogenous. However, it has been reported that $\beta$ adrenergic blockade causes increased catecholamine levels in exercise, ${ }^{23}$ and had such blockade been present in our asthmatic group, we might have noted an enhanced cGMP response during exercise because of unopposed $\alpha$ stimulation. Such an effect was not seen, although a delayed increase in cGMP occurred. Whether this delayed increase was caused by abnormal noradrenaline metabolism, or by cGMP released from the lung itself, caused by the release of chemical mediators such as histamine or from parasympathetic activity, is not known.

If a difference in the sympatho-adrenal response to exercise exists in asthmatics, it may play a role in producing EIA. Circulating adrenaline has predominant $\beta$ effects, leading to bronchodilatation and stabilisation of mast cell membranes. ${ }^{24}$ If adrenaline is not produced normally during exercise, other opposing influences on bronchial smooth muscle, such as circulating noradrenaline released from sympathetic nerve endings, histamine and other mediator substances released locally from mast cells, and vagal efferent activity, all may have a greater tendency to cause bronchoconstriction. We do not propose that the reduced sympatho-adrenal response $\rightarrow$ to exercise is the only abnormality present in asthmatics which causes them to have EIA, but its $N$ possible permissive role requires further study.

\section{References}

1 McNeill RS, Ingram CG. Effect of propranolol on ventilatory function $\mathrm{Am} J$ Cardiol 1966;18:473-5.

2 Jones RS. Significance of effect of beta blockade on $\mathbb{E}$ ventilatory function in normal and asthmatic subjects ? Thorax 1972;27:572-6.

${ }^{3}$ Griffiths J, Leung FY, Grzybowski S, Chan-Yeung MMW. Sequential estimation of plasma catecholamines in $\mathbb{D}$ exercise-induced asthma. Chest 1972;62:527-33.

- Von Euler US, Franksson C, Hellström J. Adrenaline $\varrho$ and noradrenaline output in urine after unilateral and $\underset{<}{\sigma}$ 
bilateral adrenalectomy in man. Acta Physiol Scand $1954 ; 31: 1-12$.

5 Anderson SD, Pojer R, Smith ID, Temple D. Exercise related changes in plasma levels of 15-keto-13,14dihydro-prostaglandin $F_{2} \alpha$ and noradrenaline in asthmatic and normal subjects. Scand J Respir Dis 1976; 57:41-8.

- Chryssanthopoulos C, Barboriak JJ, Fink JN, Stekiel WJ, Maksud MG. Adrenergic responses of asthmatic and normal subjects to submaximal and maximal work levels. J Allergy Clin Immunol 1978;61:17-22.

' Ball JH, Kaminsky NI, Hardman JG, Broadus AE, Sutherland EW, Liddle GW. Effects of catecholamines and adrenergic-blocking agents on plasma and urinary cyclic nucleotides in man. J Clin Invest 1972;51: 2124-9.

${ }^{8}$ Platshon LF, Kaliner M. The effects of the immunologic release of histamine upon human lung cyclic nucleotide levels and prostaglandin generation. J Clin Invest 1978; 62:1113-21.

9 Miller GJ, Davies BH, Cole TJ, Seaton A. Comparison of the bronchial response to running and cycling in asthma, using an improved definition of the response to work. Thorax 1975;30:306-11.

${ }^{10}$ Hartley JPR, Charles TJ, Seaton A. Betamethasone valerate inhalation and exercise-induced asthma in adults. Br J Dis Chest 1977;71:253-8.

${ }_{11}$ Siddle K, Kane-Maguire B, Campbell AK. The effects of glucagon and insulin on adenosine $3^{\prime}: 5^{\prime}$-cyclic monophosphate concentrations in an organ culture of mature rat liver. Biochem J 1973;132:765-73.

12 Siddle K, Davies CJ, Shetty KJ, Elkeles RS. The effect of insulin on adenosine $3^{\prime}: 5^{\prime}$-monophosphate and guanosine $3^{\prime}: 5^{\prime}$-monophosphate concentrations in human plasma. Clin Sci 1976;50:487-91.

${ }^{13}$ Sutherland EW, Rall TW. The relation of adenosine $3^{\prime}: 5^{\prime}$-phosphate and phosphorylase to the actions of catecholamines and other hormones. Pharmacol Rev 1960;12:265-99.

14 Murad F. Clinical studies and applications of cyclic nucleotides. Advances in Cyclic Nucleotides Research 1973;3:355-83.

15 Wehmann RE, Blonde L, Steiner AL. Sources of cyclic nucleotides in plasma. J Clin Invest 1974;53:173-9.

16 Vendsalu A. Studies on adrenaline and noradrenaline in human plasma. Acta Physiol Scand 1960;Supp 173: 2-123.

${ }_{17}$ Lin T. Plasma and urinary cyclic AMP levels during treadmill exercise. Clin Res 1974;22:591 (abstract).

18 Barboriak JJ, Sosman AJ, Fink JN, Maksud MG, McConnell LH, Hamilton LH. Metabolic changes in exercise-induced asthma. Clin Allergy 1973;3:83-9.

19 Barnes PJ, Brown MJ, Silverman M, Dollery CT. Catecholamines in exercise and hyperventilation-induced asthma. Clin Sci 1980;58:4p.

${ }^{20}$ Szentivanyi A. The beta adrenergic theory of the atopic abnormality in bronchial asthma. J Allergy 1968;42: 203-32.

${ }^{21}$ Conolly ME, Greenacre JK. The lymphocyte $\beta$-adrenoceptor in normal subjects and patients with bronchial asthma. J Clin Invest 1976;58:1307-16.

${ }^{22}$ Holgate ST, Baldwin CJ, Tattersfield AE. $\beta$-adrenergic agonist resistance in normal human airways. Lancet 1977;2:375-7.

${ }^{23}$ Irving $M$ H, Britton BJ, Wood WG, Padgham C, Carruthers $M$. Effects of $\beta$ adrenergic blockade on plasma catecholamines in exercise. Nature 1974;248:531-3.

${ }^{24}$ Orange RP, Austen WG, Austen KF. Immunologic release of histamine and SRS-A from human lung. I. Modulation by agents influencing cellular levels of cyclic 3' 5' adenosine monophosphate. J Exp Med 1971; 134:136s-148s. 